\title{
Coulisses
}

Revue de théâtre

40 | Hiver 2010

Jeux de rappels chez Marivaux

\section{Stéphanie Bérard, Théâtres des Antilles. Traditions et scènes contemporaines}

L'Harmatan, 2009, 220 pages

David Ball et Karine Bénac

\section{CpenEdition}

\section{Journals}

Édition électronique

URL : https://journals.openedition.org/coulisses/651

DOI : $10.4000 /$ coulisses. 651

ISSN : 2546-9460

\section{Éditeur}

Presses universitaires de Franche-Comté

Édition imprimée

Date de publication : 1 janvier 2010

Pagination : 23-25

ISBN : 978-2-84867-283-0

ISSN : 1150-594X

\section{Référence électronique}

David Ball et Karine Bénac, « Stéphanie Bérard, Théâtres des Antilles. Traditions et scènes

contemporaines », Coulisses [En ligne], 40 | Hiver 2010, mis en ligne le 30 novembre 2016, consulté le

29 décembre 2022. URL : http://journals.openedition.org/coulisses/651 ; DOI : https://doi.org/

$10.4000 /$ coulisses.651

Ce document a été généré automatiquement le 29 décembre 2022.

Tous droits réservés 


\section{Stéphanie Bérard, Théâtres des Antilles. Traditions et scènes contemporaines}

L'Harmatan, 2009, 220 pages

\section{David Ball et Karine Bénac}

\section{RÉFÉRENCE}

Stéphanie Bérard, Théâtres des Antilles. Traditions et scènes contemporaines, L'Harmatan, 2009, 220 pages, $24 €$

1 Livre bien nécessaire, et plus que jamais aujourd'hui, quand il s'agit, avec urgence, paraît-il, de mieux comprendre les Antilles, leur culture et leurs problèmes.

2 Composé de quatre chapitres qui couvrent respectivement l'histoire du théâtre antillais, ses sources et son dialogue avec le théâtre européen, le rôle de l'oralité et l'esthétique carnavalesque, l'ouvrage se veut à la fois novateur et exhaustif. Salué d'ailleurs par une préface d'Ina Césaire, il couvre de façon méthodique un domaine jusque-là peu exploré des chercheurs.

3 Le théâtre antillais est relativement inconnu pour une raison simple. Sa spécificité est sa force et sa limitation, surtout en ce qui concerne les textes écrits totalement ou en partie en créole, qui auraient trop peu de lecteurs pour assurer la rentabilité de leur publication. Ce théâtre n'est pas, pourtant, si éloigné que cela du nôtre. Comme partout, une source principale d'inspiration est l'œuvre de shakespeare, dont la pratique théâtrale était, à lui aussi, plus axée sur la représentation que sur la publication.

4 Mais pour notre part, nous ne croyons pas qu'on ait fait ailleurs une meilleure adaptation de La Tempête que celle d'Aimé Césaire (Une tempête), où un Caliban nègre mène tout consciemment sa révolte contre un Prospéro esclavagiste et impérialiste. À 
la fin de la pièce, cependant, - réalisme ou résignation ? - l'auteur laisse ensemble sur l'île ses deux protagonistes, qui doivent tant bien que mal la partager.

La Tempête revient de droit aux Antilles où elle a puisé, en partie, ses origines. En 1609, le vaisseau amiral d'une expédition colonisatrice anglaise échoua sur les côtes d'une île des Bermudes, et l'équipage arriva à y survivre neuf mois avant d'être sauvé. L'année suivante une lettre écrite par un survivant et détaillant la tempête qui avait provoqué le naufrage ainsi que la flore et la faune de l'île circula à Londres, et Shakespeare, presque certainement, en prit connaissance.

$\mathrm{Au}$ prix de lourdes subventions, qui ont forcément un côté corrupteur, la France achète une présence et un rayonnement outre-Atlantique, et accessoirement sans doute, un pardon pour deux siècles et demi d'esclavagisme, ce qui fait perpétuer pour la majorité antillaise une situation compliquée de partage et de mélange, où la collaboration et la résistance sont toutes les deux inévitables et impossibles, mais qui permet aussi une pratique théâtrale sérieuse nourrie d'une culture populaire puisant ses lointaines origines en Afrique, une culture de danse et de musique, de vaudou et de carnaval, le tout exprimé en créole. Ailleurs dans le monde développé, la culture populaire, qui n'est pour la plupart que les simplifications du cinéma, de la télévision et de la musique de variétés, est trop limitée, trop vendue et vendeuse, pour contribuer à une culture plus exigeante, sauf par ironie ou dérision. Et pourtant, c'est peut-être notre goût de l'exotisme qui nous fait estimer une cérémonie vaudou plus intéressante, plus authentique, qu'un concert rock, par exemple !

7 Tout au long du vingtième siècle, le paysage culturel antillais était dominé par Aimé Césaire, en tant qu'homme politique aussi bien qu'auteur. Le Service Municipal d'Action Culturel en Martinique, par exemple, fut sa création. Et sa fille, Ina Césaire, ethnologue et dramaturge, a assuré la continuité de son engagement, en conjuguant les deux aspects de son travail à elle, théâtral et ethnologique, dans la création de pièces inspirées des traditions orales. Dans celle, L'Enfant des passages ou La Geste de Ti-Jean, publiée, en 1987, dans ses deux versions, française et créole, elle a adapté et converti en texte littéraire un conte traditionnel, qui raconte les péripéties d'un héros partant à la recherche du pouvoir et de la richesse et qui les trouve enfin en épousant la fille du roi et en héritant de la moitié du royaume.

8 Patrick Chamoiseau, plus connu comme romancier, a fait, lui aussi, des adaptations théâtrales. En 1975, il adapta l'Antigone de Sophocle pour en faire une tragédie ponctuelle, politique et satirique, autour de la mort d'un lycéen lors des émeutes de 1971 provoquées par la visite d'un ministre français. Et quelques années plus tard, il écrivit une autre pièce qui s'attaque au conflit culturel entre noirs et blancs, Manman Dlo contre la fée Carabosse, mais cette fois-ci en utilisant la tradition des contes créoles et en pratiquant un français beaucoup plus créolisé.

9 La référence théorique principale, pour le théâtre antillais comme partout ailleurs, est aux idées de Brecht, mais Stéphanie Bérard a raison de souligner le lien, même s'il n'a pas été beaucoup revendiqué, avec celles d'Artaud, qui «s'appliquent parfaitement au théâtre antillais inspiré du rituel, qui fait prévaloir le sensoriel sur l'intellectuel, la gestuelle sur la parole, le corps sur le verbe » (p. 178), et de faire aussi le lien avec l'idée du Chaos-Monde d'Edouard Glissant, que la culture antillaise est typiquement, comme les îles elles-mêmes, éparpillée et fragmentée.

Le chapitre ayant trait à l'oralité est lui aussi très convaincant, tant dans son explicitation des différentes manifestations dramaturgiques du conteur que dans la 
relation spécifique unissant théâtre et culture de l'oralité aux Antilles. Le théâtre s'y présente donc comme un spectacle total, où chants et danse (gwoka) se taillent une place de choix dans les mises en scènes et spectacles antillais, remplaçant même parfois le jeu dramatique lui-même. Saluons d'ailleurs les références détaillées de l'auteur aussi bien aux dramaturges qu'aux mises en scène les plus novatrices et récentes.

11 Faisons, donc, nôtre la conclusion de ce livre détaillé et accessible, muni d'images en couleur, de notices biographiques et d'une bibliographie, que le théâtre antillais est important pour nous parce que ses dramaturges « remettent en question l'ordre établi, renversent les codes et les lois dans un esprit festif qui n'en est pas moins contestataire et subversif car il permet, sous couvert des masques de la fête et à l'abri d'un langage métaphorique et symbolique, de se soustraire à la sujétion et à l'aliénation culturelle et de contrer habilement un pouvoir dominant » (p. 189).

INDEX

oeuvrecitee Théâtres des Antilles. Traditions et scènes contemporaines 